\section{A review of the classification of nonstrabismic binocular vision anomalies}

\author{
Charles Darko-Takyi, ${ }^{1,2}$ \\ Naimah Ebrahim Khan, ${ }^{1}$ Urvashni Nirghin ${ }^{1}$ \\ 'Department of Optometry, University of \\ KwaZulu Natal, South Africa; \\ 2Department of Optometry, University of \\ Cape Coast, Ghana
}

\section{Abstract}

There are conflicting and confusing ideas in literature on the different types of accommodative and vergence anomalies as different authors turn to classify them differently. This paper sought to review literature on the different classifications and types of nonstrabismic binocular vision anomalies and harmonize these classifications. Search engines, namely Google scholar, Medline, Cinahl and Francis databases, were used to review literature on the classification of accommodative and vergence dysfunctions using keywords like binocular vision dysfunctions, classification of nonstrabismic binocular vision disorders or anomalies, accommodative disorders/anomalies classification and vergence disorders/anomalies classifications, and included works that described these anomalies. Nonstrabismic binocular vision anomalies are classified as accommodative and vergence anomalies. There are three different major types of accommodative anomalies, namely accommodative insufficiency, accommodative infacility (accommodative inertia), and accommodative excess (accommodative spasm), and seven different types of vergence anomalies (convergence insufficiency, convergence excess, divergence insufficiency, divergence excess, basic esophoria, basic exophoria and fusional vergence dysfunctions), which are functional in origin. Functionally, there is a commonly reported interaction between accommodative and convergence insufficiency referred to as pseudoconvergence insufficiency. Accommodative paralysis (subtype of accommodative insufficiency) and vergence anomalies - i.e., convergence paralysis, convergence spasm and divergence paralysis - are non-functional in origin with underlying systemic disease etiologies. Systemic convergence insufficiency, associated with subnormal accommodation, is a non-functional interaction between the accommodative and convergence insufficiency. The classification of nonstrabismic binocular vision anomalies is based on the description of the clinical signs and the underlying etiology either functional or non-functional in origin. Proper diagnosis and management involves investigation of the underlying etiology in addition to the battery of binocular vision test procedures.

\section{Introduction}

Many symptomatic patients' conditions do not fit specifically into one diagnostic category because of presence of defects in two or more areas of binocular vision. ${ }^{1}$ Patient's with accommodative disorders may have secondary vergence disorders and vice versa due to the control of the interactive negative feedback loop for these two systems., ${ }^{2,3}$ For example, small degrees of esophoria are usually found in cases of accommodative insufficiency, ${ }^{4}$ in this, patient uses extra innervations to overcome this accommodative disorder causing esophoria due to stimulation of accommodative convergence. ${ }^{4}$ In spite of these associations, non-strabismic binocular vision dysfunctions are classified as either accommodative anomalies or vergence anomalies. ${ }^{1}$ The aim of this review is to clarify and harmonize the classification and types of accommodative anomalies and vergence anomalies for easy comprehension and diagnosis by optometric practitioners, students and all optometric stakeholders.

\section{Search strategy}

Our search strategy involved using search engines like Google scholar, Medline, Cinahl and Francis databases to review all literature on the classification of binocular vision anomalies using keywords like binocular vision dysfunctions, classification of nonstrabismic binocular vision disorders or anomalies, accommodative disorders/anomalies classification and vergence disorders/anomalies classifications. We included works that described these anomalies.

\section{Accommodative anomalies}

Accommodative anomalies are characterized by inadequate accommodative accuracy and sustainability, inadequate amplitude, flexibility and facility and are non-refractive and non-aging neuromuscular abnormalities of the visual apparatus. ${ }^{5}$ This inadequacy affects the eyes ability to focus objects clearly causing blur retinal images. ${ }^{1}$ It is difficult to categorize accommodative anomalies, as their boundaries are not clear. ${ }^{5}$ While there are various classification systems, confusion arises as different authors classify these disorders into three, five or six differ-
Correspondence: Charles Darko-Takyi, Department of Optometry, University of Cape Coast, Cape Coast, Ghana.

Tel. +233.545063571.

E-mail: cdarko-takyi@ucc.edu.gh

Key words: Nonstrabismic binocular dysfunctions; Accommodative anomalies; Vergence anomalies.

Contributions: CD-T, conceived the idea, sought literature and drafted the paper as part of the literature review of a master's research work; NEK and UN, played a supervisory role, revised the paper critically for important intellectual content, and finally approved the paper to be published.

Conflict of interest: the authors declare no potential conflict of interest.

Acknowledgments: we wish to acknowledge Ms Carrin Martin, English editor for the school of health sciences, University of KwaZulu Natal, South Africa.

Received for publication: 12 November 2015 .

Revision received: 15 February 2016.

Accepted for publication: 19 February 2016.

This work is licensed under a Creative Commons Attribution NonCommercial 4.0 License (CC BYNC 4.0).

CCCopyright C. Darko-Takyi et al., 2016

Licensee PAGEPress, Italy

Optometry Reports 2016; 5:5626

doi:10.4081/optometry.2016.5626

ent categories, with slight or minor modifications or changes in names. The most common classifications systems are reviewed below.

\section{Donder's classification}

The original classification used for accommodative anomalies was by Donders ${ }^{4,6}$ and has been popularized by several authors. ${ }^{4,7-11}$ It has the following three categories: ${ }^{7,12}$ accommodative insufficiency, accommodative excess and accommodative infacility.

\section{Duane's classification's}

One of the early attempts to classifying accommodative anomalies was by Duane in 1915. ${ }^{4,13}$ Other authors have discussed classification of accommodative anomalies using Duane's classification with minor modifications. Scheiman and Wick, ${ }^{4}$ made reference to this system of classification instead of the popular Duke-Elder's classification. ${ }^{14}$ His six categories are: ${ }^{4}$ Insufficiency of accommodation, Ill-sustained accommodation, Inertia of accommodation or accommodative infacility, Excessive accommodation, Inequality of accommodation or unequal accommodation, and Paralysis of accommodation. 


\section{Duke-Elder Stewart's classification}

In American Academy of Optometry evidence-based guidelines on accommodative and vergence dysfunctions, ${ }^{1}$ accommodative dysfunctions were classified with reference to Duke-Elders Stewart's classification, as found in his 1949 book The practice of refraction. ${ }^{14}$ His five categories are: accommodative insufficiency, ill-sustained accommodation, accommodative infacility, paralysis of accommodation and spasm of accommodation.

In the book, The practice of refraction, ${ }^{15}$ Duke-Elder Stewart in 1963 classified accommodative anomalies into six distinct categories instead of the five in 1949. This was a minor modification to Duane's classification, and consisted of the following six anomalies: excessive accommodation, spasm of accommodation, insufficiency of accommodation, illsustained accommodation, inertia of accommodation, and paralysis of accommodation. Walsh and Hoyt (1969) made reference to the five distinct syndrome categories of anomalies of accommodation by Duke-Elder., ${ }^{5,16}$ In the book Ophthalmic optics and refraction in $1970,{ }^{17}$ as well as his publication in $1971,{ }^{18}$ Duke-Elder again emphasis his 1949 classification as: accommodative insufficiency, accommodative excess, accommodative fatigue, accommodative infacility, and accommodative paralysis.

\section{Duke-Elder and Abram's classification}

In their book, The practice of refraction published in $1993,{ }^{19}$ they emphasized Duke-Elder's five distinct anomalies specifically naming them as: insufficiency of accommodation, fatigue of accommodation, spasm of accommodation, paresis of accommodation and infacility of accommodation.

\section{Bertil Sterner's classification}

In 2001, While Bertil Sterner ${ }^{5}$ made reference to the classifications by Duke-Elder $1971,{ }^{18}$ he maintained that it was clinically useful to separate the anomalies of accommodation into one of five distinct syndrome categories: insufficiency of accommodation, fatigue of accommodation, spasm of accommodation, paresis of accommodation and infacility of accommodation. Sterner in 2001 emphasized that the five syndromes all constitute different accommodative disorders, with a range of impact on the accommodative function. ${ }^{5}$

\section{Scheiman and Wick's classification}

A more recent classification by Scheiman and Wick in $2008^{4}$ classified accommodative anomalies into four groups namely: accommodative insufficiency, ill-sustained accommodation (accommodative fatigue), accommodative excess and accommodative infacility (inertia of accommodation). This classification is functional in origin, with no underlying sys- temic etiologies, the clinical signs being purely descriptive. This system of classification originated with Donders, and expanded by DukeElder and Abram ${ }^{19}$ and has been popularized by optometric authors. ${ }^{4}$

\section{Discussion of results of classi- fications of accommodative disorders}

In Duke-Elder's classification in 1949, ${ }^{14}$ excess of accommodation was not included as found in Duane's classification previously, ${ }^{4,13}$ and included spasm of accommodation and left out inequality of accommodation. The question posed here is Is accommodative excess the same as spasm of accommodation or inequality of accommodation? If the answer is yes, then it justifies why the author replaced them with spasm of accommodation. If the answer is no, then the question posed here is why was Duane's classification in 1949 modified?

Comparing Duke-Elder's classification in $1963^{15}$ to Duane's classification in $1915,{ }^{4,13}$ Duke-Elder included spasm of accommodation and excluded inequality of accommodation. Comparing this classification with the classification in $1949^{14}$, excess of accommodation and spasm of accommodation were classified as distinct from each other in the 1963 classification $^{15}$, inferring that the two conditions were not the same. Another question posed here is Is inequality in accommodation similar to any of these conditions above?

Comparing Duke-Elder's five distinct classifications in $1949^{14}$ and 1970 or 1971, , $^{18}$ ill-sustained accommodation in 1949 was captured as fatigue of accommodation in 1970 and 1971. This raises the question as to whether ill-sustained accommodation is the same as fatigue of accommodation. It can be seen in this classification that spasm of accommodation mentioned by Duke-Elder (1963) ${ }^{15}$ is omitted in his 1970 and $1971^{18}$ publications to form the five anomalies. Comparing Duke-Elder's classification in 1949 to this classification in 1970 and 1971, spasm of accommodation mentioned in 1949 was replaced with excess of accommodation in 1970 to form the five. The question posed here reads is spasm of accommodation synonymous with excess of accommodation?

It can also be seen in Duke-Elder and Abram's classifications in $1993^{19}$ that the name fatigue of accommodation was maintained instead of ill-sustained accommodation mentioned in $1949^{14}$. In their classification again, spasm of accommodation was mentioned as compared to excess of accommodation in Duke-Elder's classification in 1970 and 1971. ${ }^{18}$

Most of the authors ${ }^{5,16,17,19}$ from 1969 made reference to the five distinct classifications by
Duke-Elder, making his system the most popular. A review of the descriptions of the specific types of accommodative anomalies will address the questions raised above, and clarify the categories of accommodative anomalies.

\section{Description of specific accom- modative disorders mentioned above}

\section{Accommodative insufficiency}

A persistently lower accommodation than expected for age is accommodative insufficiency $^{20}$ and this does not result from crystalline lens sclerosis. ${ }^{1}$ In this, the amplitude of accommodation is significantly lower than the lower limit of expected for age using Hofstetter's formula. ${ }^{4,21}$ These patients will usually exhibit a reduction in the accommodative amplitude by 2D or more. ${ }^{4,20}$ They also show a reduced positive relative accommodation, difficulty with minus lens of accommodative facility, and an increased lag of accommodation. ${ }^{1,4,20}$ Accommodative insufficiency, though as the commonest accommodative disorder $^{1,4,21}$ has the main symptom being a general asthenopia related to near ${ }^{20}$ although it also presents with other clinical signs and symptoms. ${ }^{1,4,20}$

\section{III-sustained accommodation}

This is an accommodative disorder with normal accommodative amplitude, but repeated stimulation of accommodation causes fatigue. ${ }^{1}$ Ill-sustain accommodation has been categorized as a sub classification of accommodative insufficiency ${ }^{1}$ and is also known as accommodative fatigue. ${ }^{20,21}$ On occasion, a patient might have sufficient amplitude of accommodation, but is unable to maintain the response, which may be the first stage of accommodative insufficiency. ${ }^{4,20,21}$ Patients with this disorder initially report the ability to do near work and experience discomforts after some time ${ }^{20,21}$ because the accommodative apparatus fails to maintain its effort to accommodate. With continuous near work, accommodative system loses power and near point recedes causing blur near vision; normal amplitudes of accommodation begin to deteriorate over time. ${ }^{4,21}$ For clinical diagnostic purposes, it is advisable to repeat the accommodative amplitude test several times to study the trend of results or conduct the test last in the examination procedure. The average amplitude of accommodation is calculated using Hofstetter's formula, $18.5-1 / 3$ (age). ${ }^{22}$

\section{Accommodative paralysis}

Accommodative paralysis defines sudden 
onset insufficiencies in accommodation caused by either organic disorders in the nervous system or toxins..$^{23}$ It has been categorized as a sub classification of accommodative insufficiency. ${ }^{4}$ As a rare disorder, ${ }^{1,21}$ there is a failure of the accommodative apparatus to respond to stimulus. ${ }^{1}$ Accommodative paralysis can be unilateral or bilateral, sudden or insidious,,$^{1,4,21}$ most often unilateral with extra ocular and pupillary involvement either fixed or dilated. ${ }^{1}$ This disorder can result from careless use of cycloplegic drugs, toxicity, accidents, congenital defects and diseases of the system. ${ }^{1,21}$ It has also been associated with glaucoma, and has a favorable prognosis for recovery. ${ }^{21}$ If accommodative paralysis is unilateral, it leads to the other category of accommodative dysfunction called unequal accommodation, ${ }^{4}$ a possible cause of this condition being functional amblyopia. ${ }^{4}$

\section{Accommodative excess}

Accommodative excess refers to an incessantly higher accommodative amplitude than age expected norms ${ }^{20}$, and is due to spasms of the ciliary muscle. ${ }^{21}$ Clinical signs include a lead of accommodation and reduced negative relative accommodation. ${ }^{20}$ It is often secondary to convergence insufficiency and can also be regarded as an inability to relax accommodation, known as a spasm of accommodation. ${ }^{20}$ Accommodative excess is also variously referred to as accommodative spasm, ciliary spasm and spasm of the near reflex. ${ }^{4}$ Pseudomyopia is considered as one of the signs of accommodative excess ${ }^{4}$ and patients with this condition experience discomforts with works that require the visual system to relax accommodation. ${ }^{21}$ The main symptoms are intermittent blurred vision both near and distance; the distance blur becomes worse after prolong near work or towards the end of the day and is associated with the pseudomyopia. $^{21}$ These symptoms also become worse with dim illumination. ${ }^{21}$

\section{Accommodative infacility}

Accommodative infacility, also called Inertia

Table 1. Summary of classification of accommodative anomalies.

$\begin{array}{lll}\text { Anomaly } & \text { Brief definition } & \text { Main symptoms } \\ & & \\ \begin{array}{l}\text { Functional } \\ \text { in origin }\end{array} \text { insufficiency } & \begin{array}{l}\text { Persistently lower accommodation } \\ \text { than expected for age }\end{array} & \begin{array}{l}\text { Asthenopic symptoms with } \\ \text { near point task }\end{array}\end{array}$

in origin insufficiency

\section{than expected for age near point task}

\section{Main signs

Treatment
options

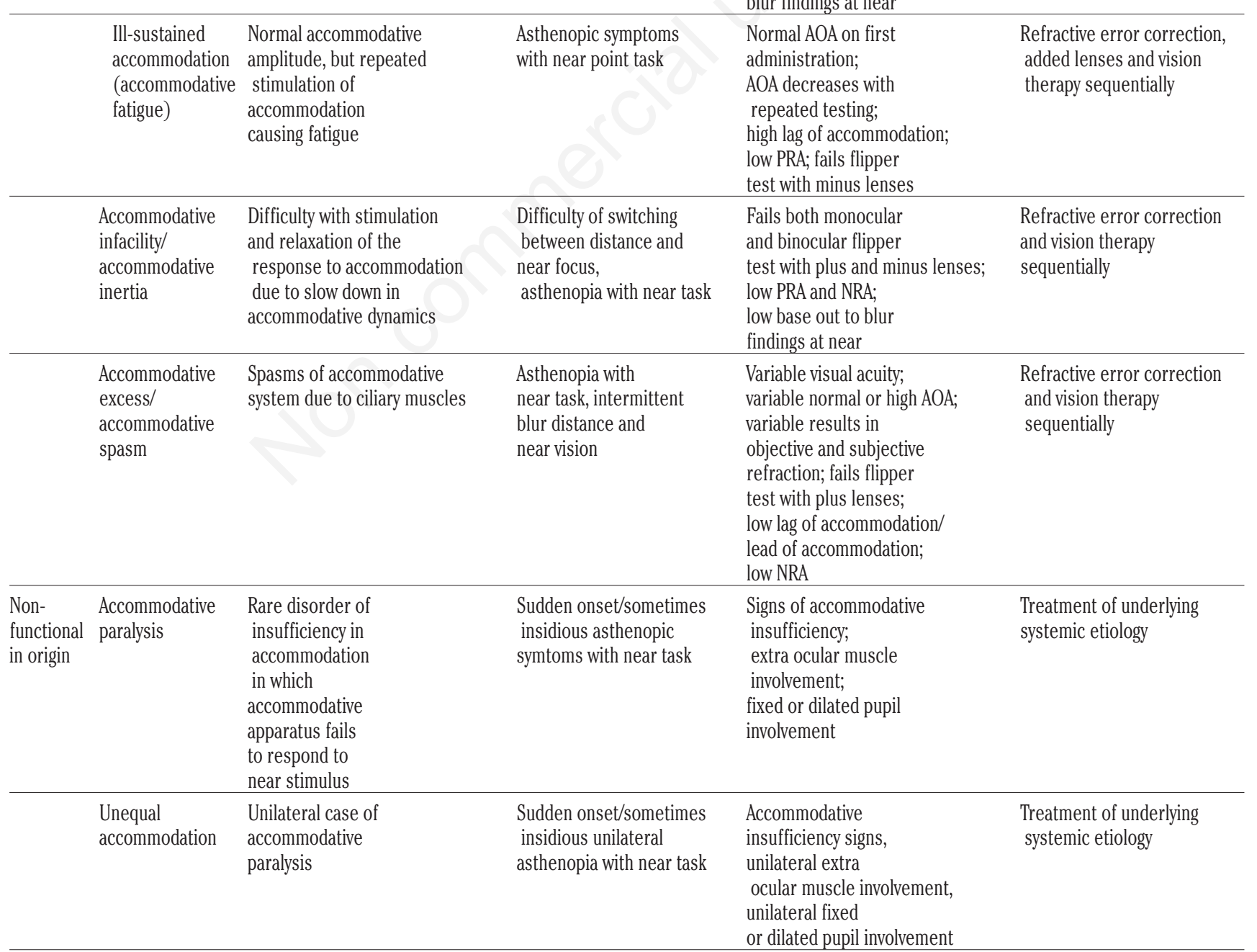
causing fatigue
AOA low for age; high lag of accommodation; low PRA; fails flipper test with minus lenses; low base out to blur findings at near Asthenopic symptoms Normal AOA on first with near point task

Refractive error correction, added lenses and vision therapy sequentially administration; high lag of accommodation; low PRA; fails flipper

both monocula low PRA and NRA: low base out to blur indings at near variable normal or high $\mathrm{AOA}$; variable results in objective and subjective test with plus lenses low lag of accommodation/ lead of accommodation; low NRA

$\begin{array}{ll}\text { Sudden onset/sometimes } & \text { Signs of accommodative } \\ \text { insidious asthenopic } & \text { insufficiency; } \\ \text { symtoms with near task } & \text { extra ocular muscle } \\ & \text { involvement; } \\ & \text { fixed or dilated pupil } \\ & \text { involvement }\end{array}$
insufficiency; extra ocular muscle involvement; fixed or dilated pupil involvement

Sudden onset/sometimes
insidious unilateral
asthenopia with near task
or dilated pupil involvement 
of accommodation ${ }^{4}$, occurs when the accommodative dynamics, that is, latency, time constant, and peak velocity are slowed. ${ }^{20,21}$ There is difficulty with stimulation and relaxation of the response to accommodation thus the main complain is difficulty changing fixation between distance and near. ${ }^{21}$ With this accommodative disorder, the change in accommodation between distance and near focus is not readily achieved and accurate due to abnormal accommodative response. ${ }^{20,21}$ Changes in accommodation only occur with effort and difficulty in the presence of normal response magnitude, ${ }^{20}$ with patients exhibiting this condition usually complaining of near-to-far or farto-near blur. ${ }^{20}$. Even though accommodative amplitude is normal; there is inadequacy in the ability of the visual system to quickly use this amplitude for longer period., ${ }^{4,21}$ The diagnosis of this disorder can thus be missed if only amplitude of accommodation is measured in clinic. ${ }^{21}$ Other accommodative tests which include monocular and binocular accommodative facility are very vital in the diagnosis of accommodative infacility. ${ }^{4}$

\section{Summary of classification of accommodative dysfunctions}

Based on the reviews of the description of the various conditions, it is now certain that unequal accommodation ${ }^{4,13}$ is a type of accommodative paralysis which is in turn a sub-classification of accommodative insufficiency. ${ }^{4}$ Accommodative fatigue (a sub-classification of accommodative insufficiency) ${ }^{4}$ is also called Illsustained accommodation. ${ }^{20,21}$ Another name for accommodative infacility is accommodative inertia, ${ }^{4}$ while accommodative excess is also called accommodative spasm. ${ }^{20}$ Different authors tend to use these terms interchangeably, with Duke-Elder's popular 1949 five distinct accommodative anomalies thus including the two sub classifications of accommodative insufficiency as specific types. Functionally, there are effectively three different major types of accommodative anomalies ${ }^{4,12}$ as first mentioned by Donders in $1854^{4,6}$ and non-functionally there are two types of accommodative anomalies which are all subtypes of accommodative insufficiency (Table 1).

\section{Vergence anomalies}

Vergence anomalies describe disjunctive movement of the eye in which there is convergence or divergence, causing the eye to inaccurately fixate and stabilize an image on the retina. ${ }^{1}$ Two classification systems exist in literature to help categorize vergence dysfunctions, namely Duane's ${ }^{24}$ and Wick's, ${ }^{25}$ which are explained below with their advantages and disadvantages.

\section{Duane's classification}

This classification divides the disorders into four main types namely convergence insufficiency, convergence excess, divergence insufficiency and divergence excess. ${ }^{24}$ This classification was originally developed by Duane for strabismus, while Tait ${ }^{26}$ in 1915 extended it to non-strabismic binocular vision anomalies., ${ }^{4,7}$ This is a descriptive classification and does not necessarily imply etiology, and Duane described and classified them as binocular commitant convergence syndromes. ${ }^{20}$ Binocular problems are described according to the type of heterophoria measured at distance and at near, so even though there are four main types, these could be grouped into two main categories, namely esophoria vergence anomalies and exophoria vergence anomalies. ${ }^{4,7,20}$ If an esophoria is larger at near than at distance and the accommodative convergence/accommodation ( $\mathrm{AC} / \mathrm{A})$ ratio is higher than normal, a convergence excess is said to exist. ${ }^{4,20}$ If the esophoria is greater at distance and a low AC/A ratio is present, a divergence insufficiency is said to exist. ${ }^{4,20}$ If an exo deviation is higher with near fixation than with distance fixation, with lower than normal AC/A ratio, then a convergence insufficiency exists. ${ }^{4,20}$ Finally, if the exo deviation is greater at distance and the AC/A ratio is higher than normal, a divergence excess exists. ${ }^{4,20}$

\section{Wick's classification}

Wick's ${ }^{25}$ classification represents an expansion of the classification by Duane, and it considers the phoria at distance and AC/A ratio. ${ }^{4,7}$ It takes all possible combinations into consideration, and indicates nine possible diagnoses, rather than the four suggested by Duane, ${ }^{4,25}$ all of which are horizontal heterophoria problems. The nine possible diagnoses can be divided into three main categories of binocular vision problems based on the AC/A ratio, the three categories being low AC/A ratio, normal AC/A ratio, and high AC/A ratio (Table 2)., ${ }^{4}$ This classification system was very specific because treatment differs for each of the conditions mentioned; ${ }^{4}$ vertical heterophorias were classified as either right or left hyperphoria. This is the classification system used by the American 0ptometric Association ${ }^{1}$ and is the most common type of classification. ${ }^{12}$ The conditions are functional in origin with purely descriptive clinical signs with no underlying system etiologies. ${ }^{4}$

\section{Comparison of Duane's classifi- cation and Wick's classification}

Other possible combinations exist in Wick's classification that do not fit into Duane's classification. ${ }^{4}$ According to Wick, Duane's classification does not have a category for a deviation in which the exo deviation and eso deviations are equal at distance and near, i.e. basic

Table 2. Possible diagnoses of binocular vision problems.

\begin{tabular}{lll} 
Wick's classification of binocular vision anomalies & Anomaly \\
Low AC/A ratio & Orthophoria at distance & Convergence insufficiency \\
& Exophoria at distance & Convergence insufficiency \\
\hline Normal AC/A ratios & Exophoria at distance & Divergence insufficiency \\
\hline & Orthophoria at distance & Fusional vergence dysfunctions \\
\hline High AC/A ratio & Exophoria at distance & Basic exophoria \\
& Esophoria at distance & Basic esophoria \\
\hline & Orthophoria at distance & Convergence excess \\
Vertical anomalies & Esophoria at distance & Convergence excess \\
\hline & Exophoria at distance & Divergence excess \\
\hline
\end{tabular}

AC/A, accommodative convergence/accommodation. 
Table 3. Summary of classification of vergence anomalies.

\begin{tabular}{|c|c|c|c|c|c|}
\hline Anomaly & & Brief definition & Main symptoms & Main signs & Treatment options \\
\hline \multirow[t]{7}{*}{$\begin{array}{l}\text { Functional } \\
\text { in origin }\end{array}$} & $\begin{array}{l}\text { Convergence } \\
\text { insufficiency }\end{array}$ & $\begin{array}{l}\text { A condition with higher } \\
\text { exophoria at near and } \\
\text { receded NPC }\end{array}$ & $\begin{array}{l}\text { Asthenopic symptoms with } \\
\text { reading and near point } \\
\text { task often long standing }\end{array}$ & $\begin{array}{l}\text { Receded NPC; } \\
\text { higher decompensated } \\
\text { exophoria at near than } \\
\text { at distance; } \\
\text { low AC/A ratio; } \\
\text { reduced PFV at near } \\
\end{array}$ & $\begin{array}{l}\text { Refractive error correction, } \\
\text { prisms or vision therapy }\end{array}$ \\
\hline & $\begin{array}{l}\text { Divergence } \\
\text { insufficiency }\end{array}$ & $\begin{array}{l}\text { A condition with high } \\
\text { esophoria at distance } \\
\text { than at near with normal } \\
\text { versions and reduced } \\
\text { divergence at distance }\end{array}$ & $\begin{array}{l}\text { Long standing intermittent } \\
\text { diplopia, especially at distance, } \\
\text { headaches and eyestrain }\end{array}$ & $\begin{array}{l}\text { Greater esophoria of } 2 \text { to } 8 \\
\text { degrees at distance than near; } \\
\text { decreased NFV at distance; } \\
\text { low AC/A ratio; normal NPC }\end{array}$ & $\begin{array}{l}\text { Refractive error correction, } \\
\text { base out prisms, } \\
\text { or vision therapy }\end{array}$ \\
\hline & $\begin{array}{l}\text { Convergence } \\
\text { excess }\end{array}$ & $\begin{array}{l}\text { A condition of a higher } \\
\text { esophoria at near than } \\
\text { at distance }\end{array}$ & $\begin{array}{l}\text { Asthenopia with reading } \\
\text { or near task, } \\
\text { occasional double vision, } \\
\text { blur vision }\end{array}$ & $\begin{array}{l}\text { Esophoria greater } \\
\text { at near than at distance; } \\
\text { high AC/A ratio; } \\
\text { reduced NFV at near }\end{array}$ & $\begin{array}{l}\text { Maximum } \\
\text { plus refractive error } \\
\text { correction, } \\
\text { minimum amount } \\
\text { of added lenses for near, } \\
\text { prisms and vision therapy }\end{array}$ \\
\hline & $\begin{array}{l}\text { Divergence } \\
\text { excess }\end{array}$ & $\begin{array}{l}\text { A condition in which } \\
\text { eye turns out } \\
\text { intermittently }\end{array}$ & $\begin{array}{l}\text { Common complaint } \\
\text { is cosmetic appearance, } \\
\text { subjective symptoms rare, } \\
\text { occasional diplopia }\end{array}$ & $\begin{array}{l}\text { Exophoria greater } \\
\text { at distance than } \\
\text { at near; high AC/A ratio; } \\
\text { essentially normal PFV } \\
\text { at near and distance; } \\
\text { no significant } \\
\text { refractive error }\end{array}$ & $\begin{array}{l}\text { Correction of any refractive } \\
\text { error, added minus lenses } \\
\text { at distance, prisms, vision } \\
\text { therapy }\end{array}$ \\
\hline & $\begin{array}{l}\text { Fusional } \\
\text { vergence } \\
\text { dysfunction }\end{array}$ & $\begin{array}{l}\text { A condition with low } \\
\text { or no degree of } \\
\text { phoria but lower } \\
\text { fusional vergence } \\
\text { reserves at distance } \\
\text { and near }\end{array}$ & $\begin{array}{l}\text { Asthenopia with } \\
\text { reading or near task }\end{array}$ & $\begin{array}{l}\text { Normal AC/A ratio; } \\
\text { normal phoria } \\
\text { at distance and near; } \\
\text { reduced fusional vergence } \\
\text { reserves at near and distance; } \\
\text { low PRA and NRA; others }\end{array}$ & $\begin{array}{l}\text { Correction of significant } \\
\text { refractive errors, vertical } \\
\text { prisms if vertical deviation } \\
\text { exists and vision therapy }\end{array}$ \\
\hline & $\begin{array}{l}\text { Basic } \\
\text { esophoria }\end{array}$ & $\begin{array}{l}\text { A condition } \\
\text { in which tonic } \\
\text { vergence is } \\
\text { high and AC/A } \\
\text { ratio is normal }\end{array}$ & $\begin{array}{l}\text { Asthenopia with } \\
\text { near and distant task }\end{array}$ & $\begin{array}{l}\text { Equal amount of } \\
\text { esophoria at distance } \\
\text { and near; normal AC/A ratio; } \\
\text { hyperopia often present }\end{array}$ & $\begin{array}{l}\text { Maximum plus prescription } \\
\text { for refractive errors, } \\
\text { horizontal relieving prisms } \\
\text { and vision therapy }\end{array}$ \\
\hline & Basic exophoria & $\begin{array}{l}\text { A condition } \\
\text { in which tonic } \\
\text { vergence is low } \\
\text { and AC/A ratio } \\
\text { normal }\end{array}$ & $\begin{array}{l}\text { Asthenopia with } \\
\text { near and distant task }\end{array}$ & $\begin{array}{l}\text { Receded NPC; } \\
\text { equal exophoria } \\
\text { at near and at distance; } \\
\text { normal AC/A ratio }\end{array}$ & $\begin{array}{l}\text { Correction of refractive } \\
\text { errors, added lenses } \\
\text { in a bifocal format for } \\
\text { full time wear, } \\
\text { horizontal relieving prism, } \\
\text { vision therapy }\end{array}$ \\
\hline \multirow[t]{3}{*}{$\begin{array}{l}\text { Non-functional } \\
\text { in origin }\end{array}$} & $\begin{array}{l}\text { Convergence } \\
\text { paralysis }\end{array}$ & $\begin{array}{l}\text { A case of convergence } \\
\text { insufficiency } \\
\text { associated with } \\
\text { serious systemic } \\
\text { disease and } \\
\text { considered a supranuclear } \\
\text { gaze disorder }\end{array}$ & $\begin{array}{l}\text { Recent or sudden } \\
\text { onset diplopia especially } \\
\text { at near and asthenopia }\end{array}$ & $\begin{array}{l}\text { All signs of functional } \\
\text { convergence insufficiency; } \\
\text { presence of serious } \\
\text { systemic disease }\end{array}$ & $\begin{array}{l}\text { Treatment of underlying } \\
\text { systemic disease }\end{array}$ \\
\hline & $\begin{array}{l}\text { Convergence } \\
\text { spasm }\end{array}$ & $\begin{array}{l}\text { Over-convergence } \\
\text { associated with } \\
\text { accommodative spasm }\end{array}$ & $\begin{array}{l}\text { Headaches, general } \\
\text { ocular discomfort, } \\
\text { blurring of vision } \\
\text { and diplopia }\end{array}$ & $\begin{array}{l}\text { Episodes of intermittent } \\
\text { maximal convergence; } \\
\text { associated } \\
\text { accommodative spasm; } \\
\text { associated pupillary } \\
\text { constrictions }\end{array}$ & $\begin{array}{l}\text { Treatment of underlying } \\
\text { systemic disease }\end{array}$ \\
\hline & $\begin{array}{l}\text { Divergence } \\
\text { paralysis }\end{array}$ & $\begin{array}{l}\text { A case of high } \\
\text { esophoria at distance } \\
\text { than at near with } \\
\text { decreased onset headaches, } \\
\text { divergence at distance } \\
\text { secondary to systemic } \\
\text { disease }\end{array}$ & $\begin{array}{l}\text { Sudden onset } \\
\text { intermittent diplopia } \\
\text { at distance, sudden } \\
\text { sudden onset eyestrain }\end{array}$ & $\begin{array}{l}\text { All clinical signs } \\
\text { of divergence insufficiency; } \\
\text { no significant refractive error; } \\
\text { presence of systemic disease }\end{array}$ & $\begin{array}{l}\text { Treatment of underlying } \\
\text { systemic disease, } \\
\text { e.g. neurological diseases }\end{array}$ \\
\hline
\end{tabular}

NPC, near point of convergence; AC/A-accommodative convergence over accommodation; PFV, positive fusional vergence; NFV, negative fusional vergence; PRA, positive relative accommodation; NRA, negative relative accommodation. 
exophoria and basic esophoria. ${ }^{4,25}$ In addition, it does not consider a condition in which there is no significant phoria at either distance or near, but the horizontal fusional vergence ranges are reduced in both base-in and baseout directions, i.e. fusional vergence dysfunction., ${ }^{427}$ Vergence anomalies have been regarded as syndromes of deterioration by some authors who have proposed a graphical analysis-based classification. ${ }^{7,8}$ However, these classifications are purely descriptive, as the mechanism of vergence is considered only in its open loop state. Some other authors indicate that these models do not estimate the contribution of proximal factor. ${ }^{7,28}$ Based on this, Wick's classification other than Duane's classification specify the binocular system in the presence of fusion. ${ }^{4,7,8}$ Scheiman and Wick utilize Wick's classification in their recent book. ${ }^{4}$

\section{Non-functional vergence anomalies}

Discussed below are vergence anomalies which are non-functional in origin but have some underlying systemic disease etiologies.

\section{Convergence paralysis}

This condition was first described by Parinaud ${ }^{29}$ as distinct from convergence insufficiency, and is a condition in which diplopia is present only at near with normal adduction and the inability to converge. ${ }^{4,22}$ This is a case of convergence insufficiency with serious underlying diseases, ${ }^{4}$ and is commonly attributed to neurological lesions in the areas of the third nerve nucleus, Corpa Quadrigemina or pineal gland (as in Parinaud's syndrome) or in debilitating diseases. ${ }^{22,30}$ This condition may present with normal, absent or reduced accommodation and the presence or absence of pupillary involvement. ${ }^{22}$ Symptoms include crossed diplopia, which presents worse at near, usually with a reduction in accommodation. ${ }^{30}$ This condition may be intentionally or unintentionally simulated in uncooperative and neurotic patients respectively, as well as in those with debilitating diseases. ${ }^{22}$

\section{Convergence spasm}

Convergence spasm is a state of over-convergence that is always accompanied by an accommodative spasm, and occurs almost exclusively in hysterical or otherwise neurotic persons. ${ }^{22}$ Patients with this condition show episodes of intermittent maximal convergence with an associated accommodative spasm and pupillary constriction. ${ }^{22}$ The symptoms are equal to that of an accommodative spasm, and can include headaches, general ocular discomfort and blurring of vision, but diplopia will usually also be reported. ${ }^{30,31}$ Functionally, patients with convergence spasm have tubular field defects; again fixating on an object closer to the eye can trigger the spasm and eyes maintain convergence after the object is removed. ${ }^{22}$

\section{Divergence paralysis}

This condition was first described by Parinaud in 1883 as a clinical entity after he observed cases of distance homonymous diplopia with normal versions and ductions. ${ }^{22,29}$ Many subsequent cases have been reported, ${ }^{22}$ and systemic diseases like tabes, poliomyelitis, disseminating sclerosis, pseudotumor cerebri, encephalitis and influenza, ${ }^{32-34}$ to mention just a few are known underlying causes

Divergence paralysis presents with all the clinical signs of divergence insufficiency, but with abnormal neurological findings ${ }^{22}$ with presence of systemic disease..$^{32-34}$ Divergence paralysis therefore is a non-functional form of divergence insufficiency but with an underlying systemic disease.

\section{Summary discussion of classifi- cation of vergence anomalies}

Vergence anomalies are classified based on their etiology either functional in origin and classification purely descriptive or non-functional in origin with underlying systemic disease etiology. Functionally, there are seven different types of vergence anomalies (Table 3) as proposed by Wick and emphasized by Scheiman and Wick in a recent book. ${ }^{4}$ Nonfunctionally vergence anomalies are classified into three, namely convergence paralysis (case of convergence insufficiency with systemic disease etiology), convergence spasm (state of over-convergence with systemic disease etiology) and divergence paralysis (state of divergence insufficiency with disease etiology). Brief descriptions of the signs, symptoms and treatment options for these anomalies are indicated (Table 3).

\section{Combined insufficiency of con- vergence and accommodation}

Discussed below are various conditions that involve an interaction of both convergence insufficiency and accommodative insufficiency.

\section{Pseudoconvergence insufficiency}

This condition has been long recognized by optometrists ${ }^{35,36}$ and by ophthalmologists. ${ }^{37} \mathrm{~A}$ typical example of a binocular vision anomaly where there is an association between accom- modation and the vergence system is pseudoconvergence insufficiency, ${ }^{4}$ and is a case of combined insufficiency of convergence and accommodation..$^{22,38}$ Pseudoconvergence insufficiency is primarily an accommodative dysfunction. ${ }^{39}$ In this case, the patient has difficulty accommodating therefore under accommodates relative to the stimulus. ${ }^{4}$ As a result, less accommodative convergence is available, the measured exophoria is large, and a greater demand is placed on positive fusional vergence. ${ }^{4}$ The differential diagnosis of true convergence insufficiency $v s$ pseudoconvergence insufficiency has been addressed in literature. ${ }^{36}$ Typically, such patients will also have a receded near point of convergence because of the reduced amplitude of accommodation and the lack of accommodative convergence. ${ }^{4}$ This case is purely functional in origin, with no underlying debilitating systemic disease or diseases; ${ }^{4}$ the classification and diagnostic clinical signs are thus purely descriptive. $^{4}$

Systemic convergence insufficiency, associated with subnormal accom-

\section{modation}

First mentioned by Duane in $1916,22,40$ Brown later in 1962 described it following some systemic diseases. ${ }^{22,41}$ Brown stated that this condition considerably differs from functional convergence insufficiency, because symptoms are more severe and the condition cannot easily resolve. Von Noorden and colleagues in 1973 also reported cases of this condition among patients who were adolescents and young adults, who apart from one, did not benefit from conventional orthoptic exercises. ${ }^{22,42}$ The onset of this condition can be gradual over many years or suddenly after an accident. ${ }^{22}$ The only difference between this condition and pseudoconvergence insufficiency is that, this is not functional in origin; there is always an underlying systemic disease. ${ }^{4,22}$

\section{Conclusions}

Despite the interaction between the accommodative and vergence systems, nonstrabismic binocular vision anomalies are classified as either accommodative anomaly or vergence anomaly. However, specific common interactions between these accommodative and vergence anomalies have been identified, a common example being the interaction between accommodative insufficiency and convergence insufficiency. These accommodative and vergence anomalies are either functional in origin and their classification purely descriptive of clinical signs or non-functional in which case there is an underlying systemic disease 
etiology in addition to the clinical signs of binocular vision. For proper diagnosis and treatment of nonstrabismic binocular vision anomalies, investigation must be made by way of the case history or underlying systemic disease in addition to the battery of binocular vision test procedures to ascertain if the cause is purely functional (innervational) or there is a disease etiology.

\section{References}

1. American Optometric Association. Care of the patient with accommodative and vergence dysfunction. Available from URL:www.aoa.org/documents/CPG-18.pdf

2. Schor CM. Fixation disparity and vergence adaptation. In: Schor CM, Ciuffreda KJ, eds. Vergence eye movements: basic and clinical aspects. Boston, MA: Butterworths, 1983. pp 465-516.

3. Ciuffreda KJ. The scientific basis for and efficacy of optometric vision therapy in non-strabismic accommodative and vergence disorders. Optometry 2002;73:73562.

4. Scheiman M, Wick B. Clinical management of binocular vision: heterophoric, accommodative, and eye movement disorders. Philadelphia, PA: Lippincott Williams \& Wilkins; 2008.

5. Sterner B. Accommodative facility training. Available from: http://www.oft.gu.se/ hp/research/theses/licentiate/2001/B_Ster ner_Lic.pdf

6. Donders F. On the anomalies of accommodation and refraction of the eye. London: New Syndeham Society; 1864.

7. Cacho-Martinez P, Garcia-Munoz A, RuizCantero MT. Is there any evidence for the validity of diagnostic criteria used for accommodative and nonstrabismic binocular dysfunctions? J Optometry 2012;7:221.

8. Dwyer P. Clinical criteria for vergence accommodation dysfunction. Clin Exp Optom 1991;74:112-9.

9. London R. Accommodation in ocular assessment. In: Barresi B, ed. Ocular assessment: the manual of diagnosis for office practice. Boston, MA: ButterworthHeinemann; 1984. pp 123-30.

10. Cooper J. Accommodative dysfunction. In: Amos J, ed. Diagnosis and management in vision care. Boston, MA: Butterworth-
Heinemann; 1987. pp 431-54.

11. Zellers J, Alpert T, Rouse M. A review of the literature and a normative study of accommodative facility. J Am Optom Assoc 1984; 55:31-7.

12. Cacho-Martinez P, Carcia-Munoz A, RuizCantero MT. Do we really know the prevalence of accommodative and nonstrabismic binocular dysfunctions? J Optometry 2010;3:185-97.

13. Daune A. Anomalies of accommodation clinically considered. Trans Am Ophthalmol Soc 1915; 1:386-400.

14. Duke-Elder S. The practice of refraction. 5th ed. St. Louis, MO: CV Mosby; 1949.

15. Duke-Elder SS. The practice of refraction. 7th ed. St. Louis, MO: CV Mosby; 1963.

16. Walsh F, Hoyt W. Clinical neuro-ophthalmology. 3rd ed. Baltimore, MD: Williams and Wilkins; 1969.

17. Duke-Elder S. System of ophthalmology. St Louis, MO: Mosby; 1970.

18. Duke-Elder S. Paresis of accommodation. Neuro-ophthalmology. London, UK: Henry Kimpton; 1971.

19. Abrams D, Duke-Elder S. Practice of refraction. Edinburgh: Churchill Livingstone; 1993.

20. Emslie R, Claassens A, Sachs N, Walters I. The near triad and associated visual problems. S Afr Optom 2007;66:184-91.

21. Rampersad N. A review of accommodation and its anomalies. Available from: www.eyesite.co.za/magazine/spotlight3.as $\mathrm{p}$

22. von Noorden GK. Anomalies of convergence and divergence. In: Van Norden GK, ed. Binocular vision and ocular motility. 4th edition. Maryland Heights, M0: Mosby; 1990. pp 500-7.

23. Duke-Elder S. System of ophthalmology. St Louis, MO: Mosby; 1961.

24. Duane A. A new classification of the motor anomalies of the eye based upon physiological principles, together with their symptoms, diagnosis, and treatment. Ann Ophthalmol 1896;1:969-1008.

25. Wick B. Horizontal deviation. In: Amos J, ed. Diagnosis and management in vision care. Boston, MA: ButterworthHeinemann; 1987.

26. Tait EF. Accommodative convergence. Am J Ophthalmol 1951;34:1093-107.

27. Grisham JD. The dynamics of fusional vergence eye movements in binocular dysfunction. Am J Optom Physiol Opt 1980;57:645-55.
28. Wick B, London R. Analysis of binocular visual function using tests made under binocular conditions. Am J Optom Physiol Opt 1987;64:227-40.

29. Parinaud H. Clinique nerveuse: paralysie des mouvements associés des yeux. Arch Neurol (Paris) 1883;5:145.

30. Evans B, Doshi S. Binocular vision and orthoptics. Oxford: ButterworthHeinemann; 2001.

31. Benjamin WJ. Borish's clinical refraction. 1st ed. Philadelphia, PA: WB Saunders Co; 1998.

32. Jampolsky A. Ocular divergence mechanisms. Trans Am Ophthalmol Soc 1971 ;68:730.

33. Dunnington JH. Paralysis of divergence with report of cases due to epidemic encephalitis. Arch Ophthalmol 1923;52:39.

34. Walsh FB, Hoyt WF. Clinical neuro-ophthalmology. Baltimore, MA: Williams \& Wilkins; 1969.

35. Grosvenor T. Primary care optometry, a clinical manual. Chicago, IL: Professional Press Inc; 1982.

36. Richman JE, Cron MT. Guide to vision therapy. South Bend, IN: Bernell Cooperation; 1988.

37. Press LJ. Pseudoconvergence insufficiency discovered by ophthalmologist. J Behav Optom 1990;1:196.

38. Barnard S. Anomalies of convergence. Investigation and treatment. Available from: www.academy.org.uk/lectures /barnard8.htm

39. University of Missouri. The convergence insufficiencies. Available from: http://www.umsl.edu/ garziar/conv_insufficiency.htm

40. Duane A. Anomalies of the accommodation, clinically considered. Arch Ophthalmol 1915;12:386-402.

41. Brown HW. Strabismus in the adult. In: Haik GM, ed. Strabismus. St Louis, MO: Mosby; 1962. p 259.

42. von Noorden GK, Brown DJ, Parks M. Associated convergence and accommodation insufficiency. Doc Ophthalmol 1973;34:393. 